\title{
The influence of sensory attributes on overall liking by a gamma regression model: an analysis of Cerrado mixed fruits jams
}

\author{
Patrícia Aparecida Pimenta PEREIRA ${ }^{1,2 *}$ (D), Vanessa Rios de SOUZA³, Maria Cecília Evangelista Vasconcelos SCHIASSI ${ }^{3}$, \\ Ana Clara Costa DIAS², Fabiana QUEIROZ³, Ana Carla Marques PINHEIRO ${ }^{3}$, Soraia Vilela BORGES 3 , \\ Marcelo Ângelo CIRILLO ${ }^{4}$
}

\begin{abstract}
Factors that influence the acceptability and preferences of consumers have been perceived as sensory attributes, such as color, appearance, flavor, and texture. Understanding which attributes are most important for overall liking would be helpful to establish meaningful criteria for product grading. Thus, in addition to the overall chemical and sensory qualities, it is important to appreciate which sensory attributes make a product pleasant or unpleasant to a consumer. In this context, the aim of this study was to evaluate the sensory attribute that contributes most to the overall liking by a gamma regression model using different formulations of mixed fruit jams made with Brazilian Cerrado fruits. Based on the proposed model, we concluded that appearance was the most important predictor of the overall liking of the assessors.
\end{abstract}

Keywords: Brazilian Cerrado fruits; simplex lattice mixture design; sensory attribute.

Practical Application: To appreciate which sensory attributes make a product pleasant or unpleasant to a consumer.

\section{Introduction}

Sensory properties are important factors in the determination of liking, and among the factors that influence the acceptability and preferences of consumers are sensory attributes, such as color, appearance, flavor, and texture (Concas et al., 2019). The sensory attributes play a major role in product acceptability by directly influencing the success of a product in the marketplace (Delahunty \& Drake, 2004).

Moskowitz \& Krieger (1995) investigated which sensory attributes are related to the acceptability of a product by consumers and whether all sensory attributes (flavor, appearance, etc.) have equal weight or have different weights in consumer preference. The authors emphasized that proper understanding of the attributes that are most important for overall liking would also be helpful for establishing meaningful criteria for product grading. According to Ritvanen et al. (2005), in addition to the overall chemical and sensory quality, it is important to appreciate which sensory attributes make a product pleasant or unpleasant to consumers.

Brazil has a wide biodiversity, and the Cerrado, which represents $25 \%$ of the Brazilian territory, houses most of these species, and the fruits of this biome are a source of bioactive compounds with functional properties beneficial to health, in addition to presenting unique sensory characteristics (Bailão et al., 2015; Souza et al., 2012a). Among its innumerable fruit trees, murici (Byrsonima crassifólia L. RICH), marolo (Annona crassiflora Mart.), jenipapo (Genipa americana L.), sweet passion fruit (Passiflora alata Dryand), and soursop (Annona muricata L.) stand out.

Many fruit species of the Brazilian Cerrado are still unknown, and therefore, few are commercially available (Mattietto et al., 2010). These fruits are of a potential interest to the agroindustry and represent a possible future source of income for the local population (Almeida et al., 2011). One way to increase availability and add even more value to exotic Brazilian fruits is to create new products, such as jams, juices and jellies, to become an option for introduction into the national and international markets (Georgiev et al., 2014).

Given the wide variety of fruits in the Brazilian Cerrado, several products can be prepared from various fruit mixtures. These fruits are capable of producing jams, jellies and juices with different tastes and appearances. Mixed fruit jams combine the sensory and nutritional aspects of two or more fruits in the final product, and this market is gradually gaining prime space in the consumer market (Schiassi et al., 2018, Farias et al., 2019; Schiassi et al., 2019).

A gamma regression model is considered in which the mean of the response variable depends on the values of the regressor variates according to an exponential link function, which is an alternative to consider for variables that seem to be highly skewed. In this context, the aim of this study was to evaluate

${ }^{1}$ Departamento de Alimentos, Escola de Nutrição, Universidade Federal de Ouro Preto - UFOP, Campus Morro do Cruzeiro, Ouro Preto, MG, Brasil

${ }^{2}$ Programa de Pós-graduação em Saúde e Nutrição, Escola de Nutrição, Universidade Federal de Ouro Preto - UFOP, Campus Morro do Cruzeiro, Ouro Preto, MG, Brasil

${ }^{3}$ Departamento de Ciência dos Alimentos, Universidade Federal de Lavras - UFLA, Lavras, MG, Brasil

${ }^{4}$ Departamento de Ciências Exatas, Universidade Federal de Lavras - UFLA, Lavras, MG, Brasil

*Corresponding author: patricia.pereira@ufop.edu.br 
the sensory attribute that contributes most to the overall liking by a gamma regression model using different formulations of mixed fruit jams made with Brazilian Cerrado fruits.

\section{Materials and methods}

\subsection{Materials}

This study used the pulp of murici (Byrsonima crassifólia L. RICH), marolo (Annona crassiflora Mart.), jenipapo (Genipa americana L.), sweet passion fruit (Passiflora alata Dryand), and soursop (Annona muricata L.) and high-pectin methoxyl (Danisco, São Paulo (SP), Brazil), citric acid and sucrose.

\subsection{Source of fruit pulps}

The pulps of jenipapo and murici were acquired from a fruit pulp processing company located in Uberlândia, Minas Gerais (MG), Brazil. The soursop pulp was obtained from a fruit pulp processing company located in Jarinu, SP, Brazil. These pulps were stored in sealed plastic bags, frozen and transported in Styrofoam boxes. The pulps of sweet passion fruit and marolo were processed at the Laboratory of Processing Plant Products, Federal University of Lavras (UFLA, Lavras, MG, Brazil), after the acquisition of fresh fruits from the north of Minas Gerais. These fruits were washed with tap water and then separated into peel, seed and pulp. The pulps were extracted manually with a knife, and the husk and seed were discarded. The pulps were then beaten in a blender and after homogenization, were stored in sealed, plastic bags and frozen. All pulp was stored in a cold room at $-18{ }^{\circ} \mathrm{C}$.

\subsection{Preparation of the jams}

To process the jams, a blend of fruit pulps was made (according to Table 1) and sucrose was added. The proportion of sugar and fruit pulp used was 1:1 (w/w). The jams were processed in an open pan that was heated with a gas flame (Macanudo, SC, Brazil). Once boiling, 1.5\% high-methoxyl pectin was added. After the soluble solids reached $75^{\circ} \mathrm{Brix}, 6 \%$ citric acid (2\%) was added and cooking was stopped. The percentages are expressed as percent weight.

The total soluble solids were determined using a portable refractometer model RT- 82 , and ${ }^{\circ}$ Brix was measured at $\pm 25^{\circ} \mathrm{C}$. The hot jams were then poured into $250 \mathrm{~mL}$ sterile bottles, cooled in a container with water and ice and stored in a refrigerator at $\pm 7^{\circ} \mathrm{C}$.

\subsection{Sensory analysis}

Prior to performing the analysis, the project was approved by the local Ethics Committee (number 0018.0.461.000-11). An acceptance test was conducted based on the attributes of color, appearance, aroma, taste, and overall liking using a 9-point hedonic scale ( 1 = extremely dislike, 9 = extremely like) and the purchase intention test using a 5-point scale (5 = definitely

Table 1. Compositions of jam mixture samples in a simplex lattice mixture design.

\begin{tabular}{|c|c|c|c|c|c|}
\hline Formulation & Jenipapo (\%) & Marolo (\%) & Murici (\%) & Soursop (\%) & Sweet passion fruit (\%) \\
\hline 1 & 100 & 0 & 0 & 0 & 0 \\
\hline 2 & 0 & 100 & 0 & 0 & 0 \\
\hline 4 & 0 & 0 & 0 & 100 & 0 \\
\hline 5 & 0 & 0 & 0 & 0 & 100 \\
\hline 7 & 50 & 0 & 50 & 0 & 0 \\
\hline 8 & 50 & 0 & 0 & 50 & 0 \\
\hline 9 & 50 & 0 & 0 & 0 & 50 \\
\hline 10 & 0 & 50 & 50 & 0 & 0 \\
\hline 14 & 0 & 0 & 50 & 0 & 50 \\
\hline 15 & 0 & 0 & 0 & 50 & 50 \\
\hline 16 & 60 & 10 & 10 & 10 & 10 \\
\hline 17 & 10 & 60 & 10 & 10 & 10 \\
\hline 18 & 10 & 10 & 60 & 10 & 10 \\
\hline 19 & 10 & 10 & 10 & 60 & 10 \\
\hline 20 & 10 & 10 & 10 & 10 & 60 \\
\hline 21 & 20 & 20 & 20 & 20 & 20 \\
\hline
\end{tabular}


would buy the product, 1 = certainly would not buy the product) (Stone et al., 2012).

The test was conducted on 85 participants ( 50 women and 35 men) between the ages of 18 and 40 years. Panelists were selected based on their regular consumption of fruit jams and jellies. In the sensory evaluation, each panelist evaluated 21 formulations in five sessions spread over five consecutive days. In the first four sessions, four formulations were evaluated, and in the fifth and final session, five formulations were evaluated.

Samples of approximately $5 \mathrm{~g}$ of jam at refrigeration temperature $\left(7^{\circ} \mathrm{C}\right)$ were served in $50 \mathrm{~mL}$ cups in a balanced manner. These samples were coded with three-digit numbers selected from a table of random numbers. The test was conducted in individual booths under white light with adequate ventilation.

\subsection{Experimental design}

From the simplex lattice mixture design (Cornell, 1983), the proportion of fruit jenipapo $\left(Z_{1}\right)$, marolo $\left(Z_{2}\right)$, murici $\left(Z_{3}\right)$, soursop $\left(Z_{4}\right)$, and sweet passion fruit $\left(Z_{5}\right)$ used in the preparation of the mixed fruit jams was determined. In total, 21 formulations were evaluated. The design with coded and experimental levels for these five factors is presented in Table 1.

Depending on the experimental results, statistical analysis based on an initial factor analysis (Hair et al., 2018) was used to describe the relationships of dependence on sensory attributes. After the identification of these variables was investigated, a generalized model (Jiang, 2006) that allows the identification of which sensory attribute $(\mathrm{x})$ is more significant in predicting the expected value of the dependent variable $(\mathrm{y})$ overall liking was used. This generalized model has a gamma distribution with a mean value $\mu>0$ and a shape (nuisance) parameter $v$ $>0$, whereas y Gamma $(\mu, v)$, if it has a density Function 1 (Mittlböck \& Heinzl, 2002).

$$
f(y)=\frac{1}{\Gamma(v)}\left(\frac{v}{\mu}\right)^{v} y^{v-1} \exp \left\{\frac{\sqrt{y}}{\mu}\right\} y>0
$$

A gamma regression is modeled using the reciprocal canonical link function $\left(\mu_{i}\right)^{-1}=x_{i} \beta, i=1, \ldots, n$, where $x_{i}$ is the vector of covariates and $\beta$ is the parameter vector to be estimated with $\beta_{0}$ as the intercept and $\beta_{1}, \ldots, \beta_{\mathrm{k}}$ as the parameters for the $\mathrm{k}$ covariates (Mittlböck \& Heinzl, 2002). The iterated procedure weighted least squares (IWLS) algorithm was used in the statistics to numerically solve the maximum likelihood equations to estimate $\beta$ in the proposed model. The diagnosis of influential observations in the estimates of model parameters is given in Function 2. This estimate, considering the dispersion parameter $\emptyset$ hat-values $\left(\mathrm{h}_{\mathrm{i}}\right)$ for a generalized linear model, can be taken directly from the final iteration of the IWLS procedure and the approximation to the Cook's distance influence measure is

$D_{i}=\frac{R_{p i}^{2}}{\hat{\phi}(k+1)} \times \frac{h_{i}}{1-h_{i}}$
$\mathrm{R}_{\mathrm{pi}}$ Standardized Pearson residuals correct for the conditional response variation and for the leverage of the observations defined in Function 3

$R_{p i}=\frac{Y_{i}-\hat{\mu}_{i}}{\sqrt{\hat{V}\left(Y_{i} \mid \eta_{i}\right)\left(1-h_{i}\right)}}$

$V\left(Y_{i} \mid \eta_{i}\right)$ is the variance of the response given the linear predictor. Finally, the validation of the presented gamma model was made considering the Q-Qplot constructed from Standardized deviance residuals defined in $\mathrm{R}_{\mathrm{Di}}$ (Function 4)

$R_{D i}=\frac{D_{i}}{\sqrt{\hat{\phi}\left(1-h_{i}\right)}}$

$\mathrm{D}_{\mathrm{i}}$, a deviance residual, is the square-roots of the case-wise components of the residual deviance, attaching the sign of $\left(Y_{i}-\hat{\mu}_{i}\right)$. For the model adjustment, the CORE TEAM software (R Core Team, 2018) was used.

\section{Results and discussion}

To investigate the dependence between the sensory attributes by using factor analysis, we obtained the factor loadings, which measure common aspects between the scores of the tasters (Table 2).

In this context, it is noted that the first factor (F1) has a strong correlation with all sensory attributes, whereas the second factor (F2) has a low correlation. Based on these results, we observe the existence of two contrasts, yielding two new variables called positive aspects of the panel (F1) and negative aspects of the panel (F2). The confirmation of these new variables can be verified by the high values of the commonalities that suggest that all sensory attributes showed a significant contribution in the formation of factors (F1) and (F2).

The scores of known factors F1 and F2 by positive and negative aspects, respectively, are shown in a Biplot following the graph (Figure 1).

Table 2. Results of sensory analysis represented by Factorial Loadings and communalities.

\begin{tabular}{lllc}
\hline \multirow{2}{*}{ Sensorial Attribute } & \multicolumn{2}{l}{ Factorial Loadings } & \\
\cline { 2 - 3 } & F1 & F2 & \\
\hline Color & 0.86 & 0.49 & 0.99 \\
Appearance & 0.85 & 0.45 & 0.93 \\
Aroma & 0.94 & 0.16 & 0.91 \\
Taste & 0.98 & -0.18 & 0.99 \\
Overall liking & 1.00 & -0.001 & 1.00 \\
Purchase Intention & 0.99 & 0.004 & 0.99 \\
Variance & 5.30 & 0.51 & 5.81 \\
Variance (\%) & 0.88 & 0.08 & 0.97 \\
\hline
\end{tabular}


The results in Figure 1 focus on the positive and negative aspects of the consumers show that the attribute appearance $\left(\mathrm{X}_{1}\right)$ is correlated with the variable color. The correlated variable color was discarded, and it was assumed that only the variable appearance was adjusted for overall liking. The aroma $\left(\mathrm{X}_{2}\right)$ and taste $\left(\mathrm{X}_{3}\right)$ variables were considered in adjusting the model because they are independent variables. The variable, purchase intention, was not considered in the model because it is correlated with the overall impression (the dependent variable selected). In this context, we considered the Gamma distribution, justified by the asymmetry in the response variable overall liking (Figure 2), to set up the model range with the following specification: $\mathrm{Y}_{\mathrm{i} 1}$ is the observed response of the $\mathrm{i}^{\text {th }}$ assessor for the variable overall liking, and $\mathrm{X}_{\mathrm{i}}$ for $\mathrm{j}=1,2,3$ refers to the responses for the variables appearance, aroma and taste, respectively. Thus, assume $\mathrm{Y}_{\mathrm{i} 1}$ is approximately $\Gamma\left(\mu_{\mathrm{ij}}, \varphi\right)$ with the systematic given by $\log \left(\mu_{\mathrm{i} 1}\right)=\alpha+\beta_{\mathrm{j}} \mathrm{X}_{\mathrm{ij}}+\gamma_{\mathrm{j}} \mathrm{X}_{\mathrm{ij}}{ }^{2}$, given that $\beta_{j}$ and $\gamma_{j}$, denote the effects of linear and quadratic $\mathrm{j}^{\mathrm{tb}}$ sensory attribute, respectively, and $\mu_{\mathrm{ij}}$.

To identify the sample that provided a greater influence over the estimates of the model parameters, the first adjustment

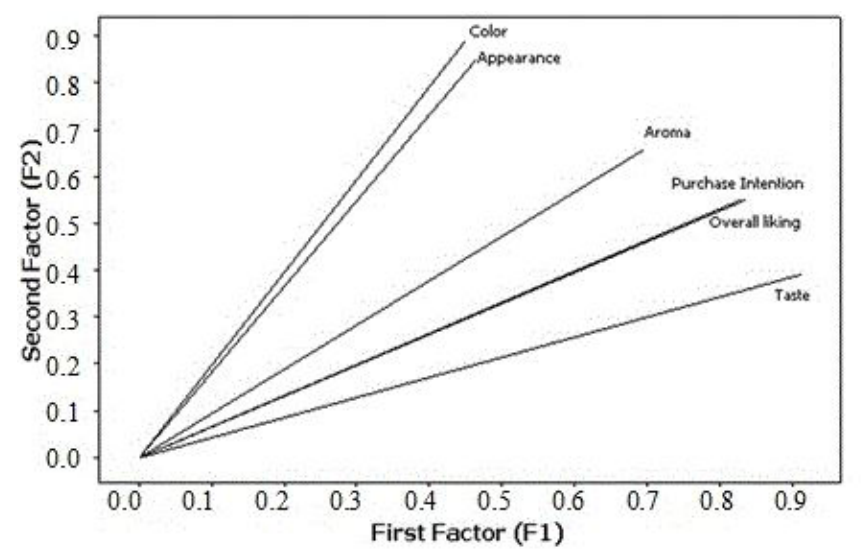

Figure 1. Biplot of sensory attributes.

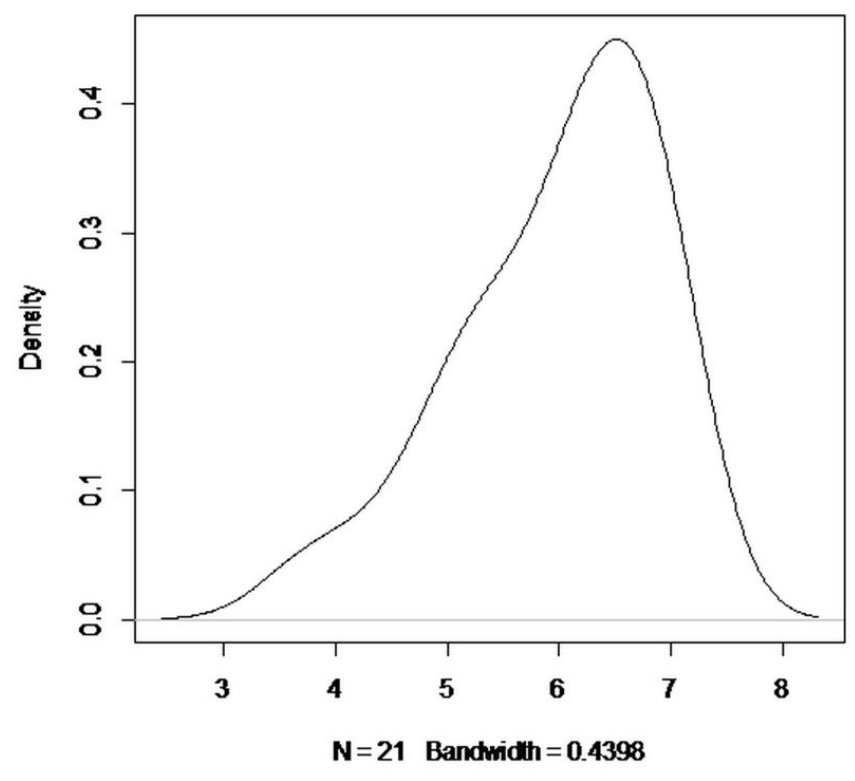

Figure 2. Density of response variable global aspect. was made considering all of the observations. The results of the diagnosis are illustrated in Figure $3 \mathrm{a}$ and $3 \mathrm{~b}$.

It can be observed that the sample 1 with the values defined in appearance $=4.350$, aroma $=4.125$, and taste $=3.337$, was identified as a point of leverage (Figure $3 \mathrm{a}$ ) and an influential observation (Figure 3b). Thus, there is statistical evidence to state that the presence of this sampling observation influences the estimates of the parameters of the fitted model. The sample represented by a formula with $100 \%$ of jenipapo fruit stood out compared to the others; this was expected because this fruit has a characteristic and pronounced flavor and aroma (Souza et al., 2012a), and an acidic,slightly sweet pulp (Souza et al., 2012b), which is often not well accepted by consumers. In addition, features such as the brown color of the fruit pulp, are not very attractive (Silva et al., 2001).

Based on the results of the observations associated with the sample diagnosis, given the identification of sample 1 (appearance $=4.350$, aroma $=4125$ and taste $=3.337$ ), and the discrepancy (Figure 3a) and influence observation (Figure 3b), we proceeded with the analysis of estimates of model parameters in two situations: 1 - with all the sample observations; 2: Withdrawal of sample 1 in this context. The results are presented below in Table 3.

Comparing the estimates of the parameters of the model with a gamma distribution set to the two situations, one can observe that, keeping or deleting sample 1, the sensory attribute with the most significant response to the overall impression is verified by the magnitude of the estimates. Thus, the appearance attribute $\left(\mathrm{X}_{1}\right)$ has a higher contribution to the composition of the model used to predict the expected value of the overall impression. In terms of validating the quality of the fit of the model in both situations, the results shown in Figures $4 \mathrm{a}$ and $4 \mathrm{~b}$ are presented.

In both cases (Figures $4 \mathrm{a}$ and $4 \mathrm{~b}$ ), the deviations are plotted within the confidence bands, and there is evidence for the model stating the distribution range used. The response has an overall print quality of fit desired.

We can observe that the appearance and its corresponding color attribute are important sensory factors. Color of foods greatly influences consumer preferences, and this trend can be observed in studies of Schiassi et al. (2018) and Schiassi et al. (2019). One of the main sensory parameters for the quality of foods is their color, and it is the first characteristic attracting consumer attention. Hence, it is considered a major feature for the assessment of food product quality (Martin et al., 2007).

In a study about consumer acceptance and appropriateness of meat substitutes in a meal context, Elzerman et al. (2011) concluded that the appropriateness seemed to be influenced by the appearance of the meat substitute-meal combination and less by flavor and texture.

The importance of color and appearance may be observed in several studies. Wei et al. (2012), for example, studied the relationship between color/appearance and sensory characteristics of expected levels. According to Wei et al. (2012), expectations and actual taste and flavor sensory characteristics are affected by food color and appearance, and according to this author 
Leverage Points

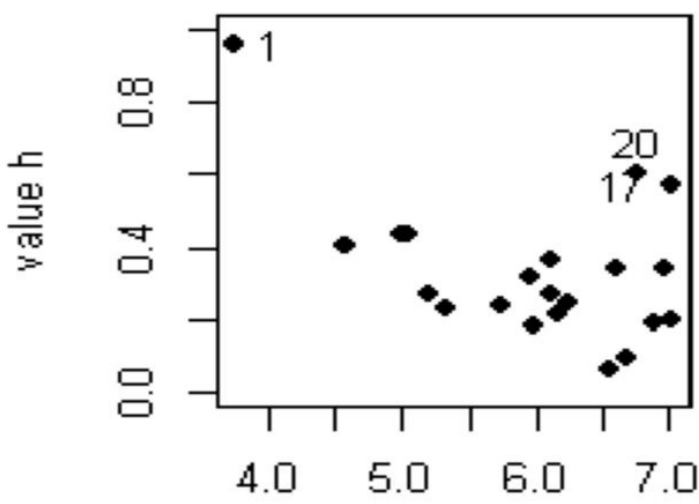

fitted values

(a)
Influence

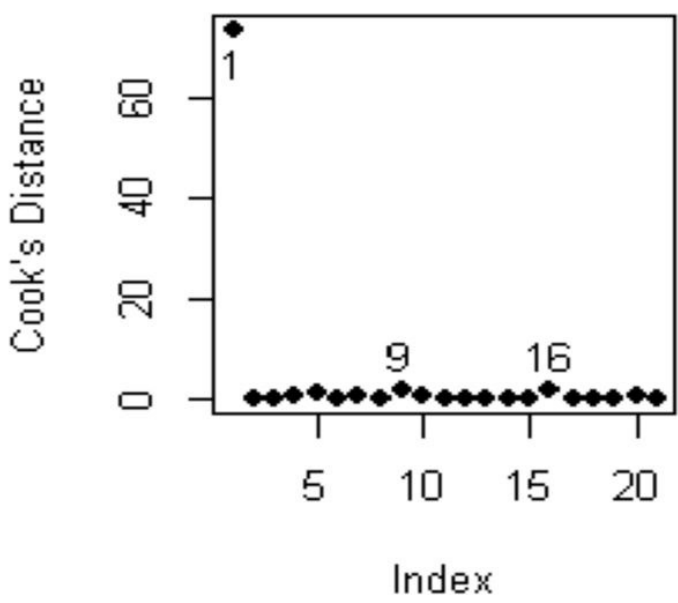

(b)

Figure 3. Diagnostic analysis of the model range set for the sensory data - point of leverage. (a) Diagnostic analysis of the model range set for the sensory data - influential observation (b).

Table 3. Estimates of the generalized model considering the distribution range for the response for overall impression according to the sensory attributes selected by means of the factor analysis.

\begin{tabular}{cccc}
\hline Parameter & Term & Situation 1 (all samples) & Situation 2 (excluding sample 1) \\
\hline$\beta_{0}$ & Intercept & -0.10 & -1.90 \\
$\beta_{1}$ & Appearance $\left(\mathrm{X}_{1}\right)$ & 0.37 & 0.71 \\
$\beta_{2}$ & Aroma $\left(\mathrm{X}_{2}\right)$ & 0.005 & 0.30 \\
$\beta_{3}$ & Taste $\left(\mathrm{X}_{3}\right)$ & 0.06 & 0.002 \\
$\gamma_{1}$ & $\mathrm{X}_{1}{ }^{2}$ & -0.03 & -0.05 \\
$\gamma_{2}$ & $\mathrm{X}_{2}{ }^{2}$ & 0.001 & -0.02 \\
$\gamma_{3}$ & $\mathrm{X}_{3}{ }^{2}$ & 0.003 & 0.008 \\
\hline
\end{tabular}

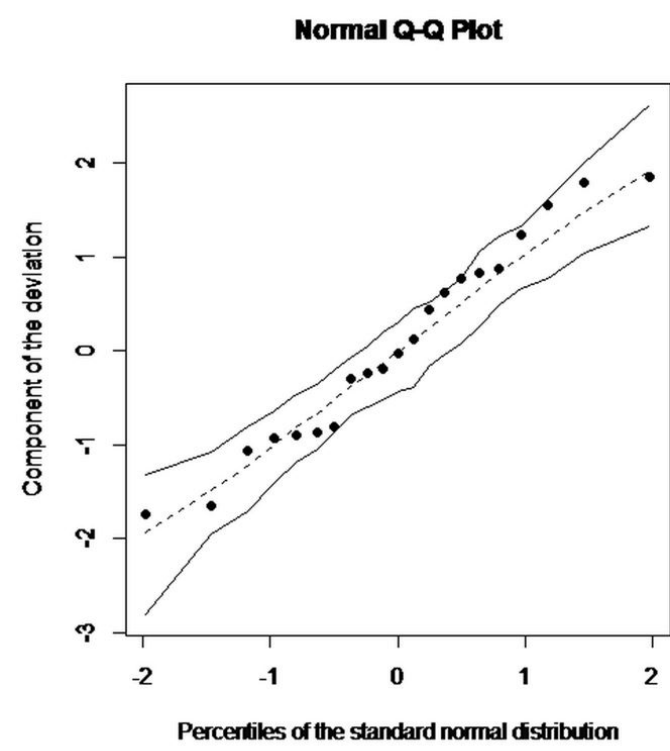

Normal QQ Plot

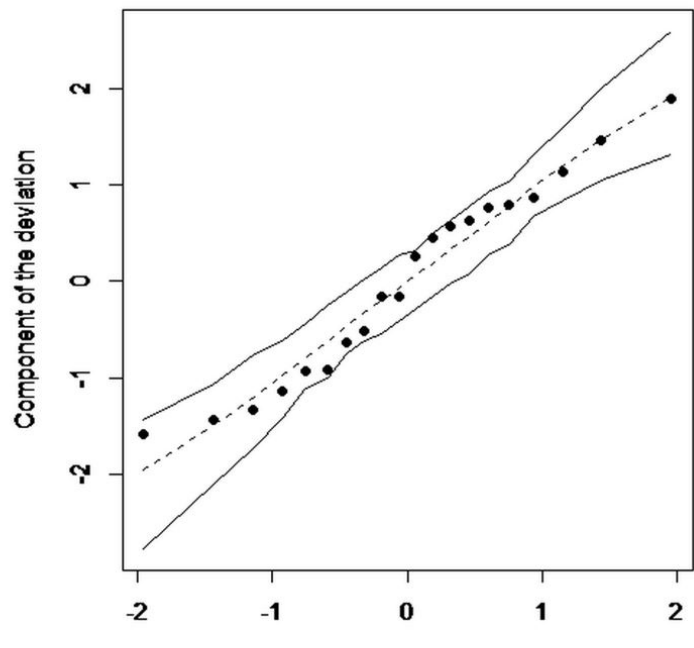

Percentiles of the standard nomal distribution (b)

Figure 4. Chart of the envelope simulated considering the model range set for all observations (situation 1); (a) Chart of the envelope simulated considering the model range set for excluding sample 1 (situation 2) (b). 
in many studies, it was found that color affected the expected and perceived levels of sensory characteristics. In general, they suggested that vivid colors tend to arouse stronger tastes or flavors than pale colors.

\section{Conclusions}

The proposed gamma regression model allowed us to infer that the attribute, appearance, showed a greater contribution to the prediction of the expected overall liking of the assessors.

\section{Acknowledgements}

The authors wish to thank the financial support of Conselho Nacional de Desenvolvimento Científico e Tecnológico (CNPq), Fundação de Amparo à Pesquisa do Estado de Minas Gerais (FAPEMIG) and Coordenação de Aperfeiçoamento de Pessoal de Nível Superior (CAPES).

\section{References}

Almeida, M. M. B., de Sousa, P. H. M., Arriaga, Â. M. C., do Prado, G. M., Magalhães, C. E. C., Maia, G. A., \& de Lemos, T. L. G. (2011). Bioactive compouds and antioxidant activity of fresh exotic fruits from northeastern Brazil. Food Research International, 44(7), 21552159. http://dx.doi.org/10.1016/j.foodres.2011.03.051.

Bailão, E. F., Devilla, I., da Conceição, E., \& Borges, L. (2015). Bioactive compounds found in Brazilian Cerrado fruits. International Journal of Molecular Sciences, 16(10), 23760-23783. http://dx.doi.org/10.3390/ ijms161023760. PMid:26473827.

Concas, M. P., Catamo, E., Biino, G., Toniolo, D., Gasparini, P., \& Robino, A. (2019). Factors associated with food liking and their relationship with metabolic traits in Italian cohorts. Food Quality and Preference, 75, 64-70. http://dx.doi.org/10.1016/j.foodqual.2019.02.010.

Cornell, J. A. (1983). Experiment with mixtures: design, models and analysis of mixtures data. New York: John Wiley.

Delahunty, C. M., \& Drake, M. A. (2004). Sensory characteristics of cheese and its evaluation. In P. F. Fox, P. L. H. McSweeney, T. M. Cogan, \& T. P. Guinee (Eds.), Cheese, chemistry, physics and microbiology. London: Elsevier.

Elzerman, J. E., Hoek, A. C., Van Boekel, M. A. J. S., \& Luning, P. A. (2011). Consumer acceptance and appropriateness of meat substitutes in a meal context. Food Quality and Preference, 22(3), 233-240. http://dx.doi.org/10.1016/j.foodqual.2010.10.006.

Farias, T. R. T., Schiassi, M. C. E. V., Pereira, P. A. P., Souza, V. R., Lago, A. M. T., Borges, S. V., \& Queiroz, F. (2019). Mixed Brazilian Cerrado fruits preserves without added sugar: the effect of bodying agents. British Food Journal, 121(9), 1969-1981. http://dx.doi.org/10.1108/ BFJ-11-2018-0739.

Georgiev, V., Ananga, A., \& Tsolova, V. (2014). Recent advances and uses of grape flavonoids as nutraceuticals. Nutrients, 6(1), 391-415. http://dx.doi.org/10.3390/nu6010391. PMid:24451310.

Hair, J. F., Babin, B. J., Anderson, R. E., \& Black, W. C. (2018). Multivariate data analysis (8th ed.). India: Cengage India.
Jiang, J. (2006). Linear and generalized linear mixed models and their applications. London: Springer.

Martin, M. L. G. M., Ji, W., Luo, R., Hutchings, J., \& Heredia, F. J. (2007). Measuring colour appearance of red wines. Food Quality and Preference, 18(6), 862-871. http://dx.doi.org/10.1016/j.foodqual.2007.01.013.

Mattietto, R. A., Lopes, A. S., \& Menezes, H. C. (2010). Physical and physicochemical characterization of caja fruit (Spondias mombin L.) and its pulp, obtained using two types of extractor. Brazilian Journal of Food Technology, 13(3), 156-164. http://dx.doi.org/10.4260/ BJFT2010130300021.

Mittlböck, M., \& Heinzl, H. (2002). Measures of explained variation in gamma regression models. Communications in Statistics. Simulation and Computation, 31(1), 61-73. http://dx.doi.org/10.1081/SAC-9687282.

Moskowitz, H., \& Krieger, R. (1995). The contribution of sensory liking to overall liking: an analysis of six food categories. Food Quality and Preference, 6(2), 83-90. http://dx.doi.org/10.1016/09503293(95)98552-T.

R Core Team. (2018). R: A Language and Environment for Statistical Computing. Vienna: R Foundation for Statistical Computing.

Ritvanen, T., Lampolahti, S., Lilleberg, L., Tupasela, T., Isoniemi, M., Appelbye, U., Lyytikainen, T., Eerola, S., \& Uusi-Rauva, E. (2005). Sensory evaluation, chemical composition and consumer acceptance of full fat and reduced fat cheeses in the Finnish market. Food Quality and Preference, 16(6), 479-492. http://dx.doi.org/10.1016/j. foodqual.2004.10.001.

Schiassi, M. C. E. V., Lago, A. M. T., Souza, V. R., Meles, J. S., Resende, J. V., \& Queiroz, F. (2018). Mixed fruit juices from Cerrado: optimization based on sensory properties, bioactive compounds and antioxidant capacity. British Food Journal, 120(10), 2334-2348. http://dx.doi. org/10.1108/BFJ-12-2017-0684.

Schiassi, M. C. E. V., Salgado, D. L., Meirelles, B. S., Lago, A. M. T., Queiroz, F., Curi, P. N., Pio, R., \& de Souza, V. R. (2019). Berry Jelly: optimization through desirability-based mixture design. Journal of Food Science, 84(6), 1522-1528. http://dx.doi.org/10.1111/17503841.14634. PMid:31120586.

Silva, D. B., Silva, J. A., Junqueira, T. V., \& Andrade, L. R. M. (2001). Cerrado' fruits. Brasília: Embrapa Informação Tecnológica.

Souza, V. R., Pereira, P. A. P., Pinheiro, A. C. M., Nunes, C. A., Silva, T. L. T., Borges, S. V., \& Queiroz, F. (2012a). Multivariate approaches for optimization of the acceptance: optimization of a brazilian cerrado fruit jam using mixture design and parallel factor analysis. Journal of Sensory Studies, 27(6), 417-424. http://dx.doi.org/10.1111/joss.12005.

Souza, V. R., Pereira, P. A. P., Queiroz, F., Borges, S. V., \& Carneiro, J. D. S. (2012b). Determination of bioactive compounds, antioxidant activity and chemical composition of Cerrado Brazilian fruits. Food Chemistry, 134(1), 381-386. http://dx.doi.org/10.1016/j. foodchem.2012.02.191.

Stone, H., Bleibaum, R., \& Thomas, H. A. (2012). Sensory evaluation practices (4th ed.). New York: Academic Press.

Wei, S. T., Ou, L. C., Luo, M. R., \& Hutchings, J. B. (2012). Optimisation of food expectations using product colour and appearance. Food Quality and Preference, 23(1), 49-62. http://dx.doi.org/10.1016/j. foodqual.2011.07.004. 